\title{
(6) OPEN ACCESS \\ Prediction of school outcome after preterm birth: a cohort study
}

David Odd, ${ }^{\oplus 1,2}$ David Evans, ${ }^{1}$ Alan M Emond ${ }^{2}$

- Additional material is published online only. To view please visit the journal online (http://dx.doi.org/10.1136/ archdischild-2018-315441)

${ }^{1}$ Neonatal Unit, North Bristol NHS Trust, Bristol, UK

${ }^{2}$ Population Health Sciences, Bristol Medical School, University of Bristol, Bristol, UK

\section{Correspondence to}

Dr David Odd, Neonatal Unit, Southmead Hospital, Bristol BS10 5NB, UK;

david.odd@bristol.ac.uk

Received 1 May 2018

Revised 6 September 2018

Accepted 10 September 2018

\begin{abstract}
Objective To identify if the educational trajectories of preterm infants differ from those of their term peers.

Design This work is based on the Avon Longitudinal Study of Parents and Children (ALSPAC). Educational measures were categorised into 10 deciles to allow comparison of measures across time periods. Gestational age was categorised as preterm (23-36 weeks) or term (37-42 weeks). Multilevel mixed-effects linear regression models were derived to examine the trajectories of decile scores across the study period. Gestational group was added as an interaction term to assess if the trajectory between educational measures varied between preterm and term infants. Adjustment for possible confounders was performed.
\end{abstract}

Subjects The final dataset contained information on 12586 infants born alive at between 23 weeks and 42 weeks of gestation.

Main outcome measures UK mandatory educational assessments (SATs) scores throughout educational journal (including final GCSE results at 16 years of age).

Results Preterm infants had on average lower Key Stage (KS) scores than term children $(-0.46(-0.84$ to $-0.07)$ ). However, on average, they gained on their term peers in each progressive measure $(0.10(0.01$ to 0.19$)$ ), suggesting 'catch up' during the first few years at school. Preterm infants appeared to exhibit the increase in decile scores mostly between KS1 and KS2 ( $p=0.005)$ and little between KS2 and KS3 ( $p=0.182)$ or KS3 and KS4 $(p=0.149)$.

Conclusions This work further emphasises the importance of early schooling and environment in these infants and suggests that support, long after the premature birth, may have additional benefits.

\section{INTRODUCTION}

Preterm birth is a relatively common event, with 6\% of infants being born 4 or more weeks before their due date. ${ }^{1}$ However, both extreme preterm birth and less severe prematurity carries a higher risk of mortality, ${ }^{2}$ and long-term cognitive, ${ }^{3}$ educational, ${ }^{4}$ psychiatric $^{4}$ and social impacts ${ }^{5}$ for the infant. We have recently shown that preterm infants were more likely to struggle at school, ${ }^{16}$ especially those enrolled in school a year earlier due to their prematurity. However, while this effect was measurable throughout their educational journey (up to the age of 16), it is unclear if preterm infants demonstrate 'catch up' as they grow, ${ }^{7}$ or alternatively begin to struggle more as the demands on them become more complex. The primary aim of this work is to identify if early educational measures are more, or less, predictive of final attainment in preterm

\section{What is already known on this topic?}

Preterm birth is a relatively common event, with $6 \%$ of infants being born 4 or more weeks before their due date.

- Ex-preterm children are more likely to struggle at school than term peers.

- It is unclear if preterm infants demonstrate 'catch up' or begin to struggle more as they grow.

\section{What this study adds?}

Early educational measures are correlated with later measures.

- The trajectory of educational measures in preterm infants varies compared with that of their term peers.

- Most of the 'catch up' seems to occur in the first few years at school.

infants than term infants, and if the educational trajectories of preterm infants differ from those of their term peers.

\section{METHODS}

Avon Longitudinal Study of Parents and Children (ALSPAC) recruited 14541 pregnant women resident in Avon, UK, with expected dates of delivery from 1 April 1991 to 31 December $1992 .{ }^{89}$ Briefly, 14541 pregnancies were initially enrolled. Of these initial pregnancies, there was a total of 14062 live births and 13988 children who were alive at 1 year of age. More information can be found on the ALSPAC website: www.alspac.bristol.ac.uk.

Outcome measures for this work were derived from the routine educational assessments mandatory in state schools in England which were linked to the ALSPAC study. In England, a child's educational journey at school is split into four 'Key Stages', with assessments at the end of each stage: Key Stage 1 (KS1) (ages 5-7 years), Key Stage 2 (KS2) (ages 7-11 years), Key Stage 3 (KS3) (ages 11-14 years) and Key Stage 4 (KS4) (ages 14-16 years). For the predictive models, a poor outcome at age 16 (KS4) was defined as not obtaining 5 GCSE passes at A* to C level. This is consistent with our previous work and provide a more meaningful measure for interpretation. ${ }^{6}$ Where comparisons across KSs were needed, the summary measures were categorised into 10 deciles to allow comparison of measures across time periods. Gestational 
age at birth was prospectively recorded from the clinical notes and if less than 37 weeks was then confirmed after reviewing the clinical records. Gestational age was categorised as preterm $\left(23^{+0}\right.$ to $36^{+6}$ weeks $)$ or term $\left(37^{+0}\right.$ to $42^{+6}$ weeks $)$.

Potential confounders between gestation at birth and educational outcome were identified a priori ${ }^{10}$ and split into three groups:

Table 1 Characteristics of study population

\begin{tabular}{|c|c|c|c|c|}
\hline Measure & $\begin{array}{l}\text { Number } \\
\text { with data }\end{array}$ & $\begin{array}{l}\text { Preterm } \\
(\mathrm{n}=775)\end{array}$ & $\begin{array}{l}\text { Term } \\
(n=11811)\end{array}$ & $P$ values \\
\hline \multicolumn{5}{|l|}{ Prepregnancy factors } \\
\hline Maternal age & 12586 & $27.5(4.9)$ & $27.9(5.0)$ & 0.0247 \\
\hline $\begin{array}{l}\text { Maternal } \\
\text { socioeconomic group }\end{array}$ & 9052 & & & 0.930 \\
\hline I-Professional & & $22(4.3 \%)$ & $460(5.5 \%)$ & \\
\hline li-Managerial & & $158(31.0 \%)$ & $2610(31.0 \%)$ & \\
\hline $\begin{array}{l}\text { iiiN—Skilled non- } \\
\text { manual }\end{array}$ & & $41(8.1 \%)$ & $685(8.0 \%)$ & \\
\hline $\begin{array}{l}\text { iiiM-Skilled } \\
\text { manual }\end{array}$ & & $228(44.8 \%)$ & $3729(43.7 \%)$ & \\
\hline iv-Semiskilled & & $49(9.6 \%)$ & $863(10.1 \%)$ & \\
\hline v-Unskilled & & $11(2.2 \%)$ & $196(2.3 \%)$ & \\
\hline $\begin{array}{l}\text { Mother's highest } \\
\text { educational } \\
\text { qualification* }\end{array}$ & 11175 & & & 0.005 \\
\hline CSE & & $170(26.4 \%)$ & $2182(20.7 \%)$ & \\
\hline Vocational & & $70(10.9 \%)$ & $1079(10.2 \%)$ & \\
\hline 0 level & & $205(31.9 \%)$ & $3730(35.4 \%)$ & \\
\hline A level & & $137(21.3 \%)$ & $2291(21.8 \%)$ & \\
\hline Degree & & $61(9.5 \%)$ & $1250(11.9 \%)$ & \\
\hline Non-white ethnicity & & $66(9.3 \%)$ & $488(4.5 \%)$ & $<0.001$ \\
\hline \multicolumn{5}{|c|}{ Antenatal and intrapartum factors } \\
\hline Primiparous & 11632 & $348(48.7 \%)$ & $4804(44.0 \%)$ & 0.227 \\
\hline Maternal hypertension & 12585 & $105(13.6 \%)$ & $406(3.4 \%)$ & $<0.001$ \\
\hline Multiple birth & 12586 & $149(19.2 \%)$ & $186(1.6 \%)$ & $<0.001$ \\
\hline Delivery & 11465 & & & $<0.001$ \\
\hline Spontaneous cephalic & & $427(58.3 \%)$ & $8191(76.3 \%)$ & \\
\hline $\begin{array}{l}\text { Emergency caesarean } \\
\text { section }\end{array}$ & & $166(22.7 \%)$ & $624(5.8 \%)$ & \\
\hline $\begin{array}{l}\text { Elective caesarean } \\
\text { section }\end{array}$ & & $40(5.5 \%)$ & $449(4.2 \%)$ & \\
\hline Instrumental & & $62(8.5 \%)$ & $1323(12.3 \%)$ & \\
\hline Breech & & $37(5.1 \%)$ & $146(1.4 \%)$ & \\
\hline \multicolumn{5}{|c|}{ Infant and postpartum factors } \\
\hline Male & 12586 & $443(57.2 \%)$ & $6033(51.1 \%)$ & 0.001 \\
\hline Birth weight (g) & 12441 & 2347 (615) & $3456(485)$ & $<0.001$ \\
\hline Birth length (cm) & 9518 & $47.0(2.6)$ & $50.8(2.3)$ & $<0.001$ \\
\hline $\begin{array}{l}\text { Head circumference } \\
(\mathrm{cm})\end{array}$ & 9664 & $32.4(2.1)$ & $34.9(1.4)$ & $<0.001$ \\
\hline Apgar at $1 \mathrm{~min}$ & 11467 & $9(7-9)$ & $9(8-9)$ & $<0.001$ \\
\hline Apgar at $5 \mathrm{~min}$ & 11467 & $9(9-10)$ & $10(9-10)$ & $<0.001$ \\
\hline Received resuscitation & 11452 & $182(24.9 \%)$ & $838(7.8 \%)$ & $<0.001$ \\
\hline
\end{tabular}

SD are given for means of normally distributed continuous variables and percentages for proportions.

${ }^{*} \mathrm{CSE}=$ Certificate in Secondary Education (commonly taken at 16 years of age); Vocational=City \& Guilds (intermediate level), technical, shorthand or typing, or other qualification; 0 level=Ordinary level (commonly taken at 16 years of age); A level=Advanced level (commonly taken at 18 years of age), state enrolled nurse, state registered nurse, City \& Guilds (final or full level) or teaching qualification; Degree=University degree
- Social factors: maternal age, socioeconomic group ${ }^{11}$ and education and ethnicity.

- Antenatal factors: gender, parity, weight, length and head circumference at birth.

- Intrapartum factors: mode of delivery and maternal hypertension.

The dataset contained information on 13991 infants born alive at between 23 weeks and 42 weeks of gestation. Infants were defined as preterm $(n=898)$ or term $(n=13093)$. A total of 1405 infants did not have outcome measures available, leaving 12586 infants. The dataset used has been described in our previous work, ${ }^{6}$ but in brief, infants excluded from the analysis were more likely to have older mothers, with higher socioeconomic status and more educational qualifications. The excluded infants were more likely to be male, had lower Apgar scores and were more likely to have received resuscitation at birth.

Initially, the demographics of the population, split by gestational age category, were described, and then correlations between the $10 \mathrm{KS}$ deciles were derived, and the proportions of infants having a low score at each measure were assessed. The proportion of infants scoring each combination of KS1 and KS4 deciles was then plotted, split by gestational status.

A multiple imputation data technique (chained equations) was used to minimise any potential selection bias in the multivariable models (below) and to facilitate reporting on the same number of subjects for crude and adjusted analyses. ${ }^{12}$ These models were derived using all the variables presented in this paper (including exposure and outcome variables). Analysis was limited to infants with gestational age and the appropriate outcome measure (ie, imputed outcome values were not used).

Receiver operating characteristic (ROC) curves were then produced to investigate how well KS1 scores could predict a low KS4 score, and if gestational age modified the relationship. Adjustment for possible confounders was next performed by adding the potential confounders to the regression models, in the blocks of common variables defined above (eg, social factors). The model was then repeated using KS2 and KS3 measures instead of KS1.

Finally, multilevel mixed-effects linear regression models were then derived to examine the trajectories of decile scores across the study period. Dependent variables were the KS decile, while explanatory measures were age, preterm status and other covariates (see above). Data were treated as clustered by child, and overall linear changes between KS measures were assessed using the Stata command 'xtmixed'. Gestational group was added as an interaction term to assess if the trajectory between educational measures varied between preterm and term infants. Adjustment for possible confounders was performed as above. In a sensitivity analysis, this model was repeated to assess if the results were attenuated after adjustment for infants in receipt of special educational needs support. In a final sensitivity analysis, the model was repeated and tested, including only preterm infants, to test if the trajectory of their educational performance was modified by whether they were in the correct school year (due to a discrepancy between their estimated date of delivery and actual date of birth) or not.

All analyses were conducted with Stata V.14. Results are presented as $\mathrm{OR}(95 \% \mathrm{CI})$, mean (SD), median (IQR) or number (\%).

\section{RESULTS}

The cohort is drawn from the ALSPAC cohort and is identical to our previous work. ${ }^{6}$ The median gestation was 35 (IQR 


\begin{tabular}{|c|c|c|c|c|}
\hline & KS1 & KS2 & KS3 & KS4 \\
\hline KS1 & 1 & & & \\
\hline KS2 & 0.78 (0.78 to 0.79 ) & 1 & & \\
\hline KS3 & 0.67 (0.65 to 0.68$)$ & 0.81 (0.81 to 0.82 ) & 1 & \\
\hline KS4 & 0.63 (0.61 to 0.64 ) & 0.73 (0.72 to 0.74 ) & 0.73 (0.72 to 0.74$)$ & 1 \\
\hline
\end{tabular}

Numbers are correlation coefficients $(95 \% \mathrm{Cl})$.

All $p$ values $<0.001$.

KS, Key Stage.

33-36) weeks in the preterm group and 40 (IQR 39-41) in the term group. Demographics of the infants are shown in table 1. Preterm infants varied from term infants in a number of ways. Of note, they had lower birth weights, lengths and head circumferences, lower Apgar scores and were more likely to be born as multiple births. The distributions of four KS scores, overlaid with the derived deciles (and the mean score per decile), are shown in the online supplementary appendix.

Preterm infants had a higher chance of being in the lowest decile at all four assessments than their term peers (KS1: 139 (17.9\%) vs 1310 (11.1\%), p<0.001; KS2 91 (11.7\%) vs 1079 (9.1\%), p=0.015; KS3 74 (9.6\%) vs 875 (7.4\%), p=0.029, KS4 $102(12.2 \%)$ vs $1039(8.8 \%), \mathrm{p}<0.001)$. Correlations of low KS scores were attenuated by the length of time that passed between the two assessments (table 2), with the highest correlation being between a KS2 and KS3 measure $(0.81(0.81-0.82))$ and the lowest between a KS1 and KS4 measure $(0.63$ (0.61-0.64)). Figure 1 shows the summary measures of KS scores at each time point, split by gestational age.

ROC curves showed that the mean area under the curve for predicting a low score at KS4 ranged from $0.83(0.82-0.84)$ in the model only containing KS1 to $0.89(0.88-0.89)$ in the saturated model using KS2 as the educational measure (table 3). There was little overall evidence that preterm status modified the predictive value of KS 1, 2 or 3 deciles on a final low KS4 score.

Table 4 shows summary results from the mixed linear model. Over the four measures, preterm infants tended a have a mean decile score around 0.5 lower than term infants $(-0.46(-0.84$ to -0.07$))$. There was also strong evidence that preterm infants gained around a tenth of a decile on their term peers in each progressive measure $(0.10(0.01$ to 0.19$))$, suggesting that preterm infants exhibited a different trajectory to term infants. When looking at the difference between each measure, preterm infants appeared to exhibit the increase in decile scores mostly between KS1 and KS2 (0.34 (0.10 to 0.58$)$ ) and little between KS2 and KS3 (p=0.182) or between KS3 and KS4 $(p=0.149)$. Adding the variable of special educational needs support to the model produced compatible results to the main analysis (trajectory difference $0.11 \quad(0.01$ to 0.20$), p=0.025)$. In a model containing just preterm infants, there was little evidence that infants placed in the incorrect school year due to their prematurity had a different profile of 'catch up' in their deciles than those in the correct school year $(\mathrm{p}=0.130)$.

Finally, the analysis was repeated, splitting the preterm cohort by those born extremely preterm $\left(23^{+0}\right.$ to $31^{+6}$ weeks of gestation, $\mathrm{n}=101)$, and those moderate/late preterm $\left(32^{+0}\right.$ to $36^{+6}$ weeks of gestation, $n=674$ ) (table 5). For the moderate/late preterm infants, results were entirely compatible with the main analysis. For the extremely preterm infants, overall trajectory was similar to the main analysis $(0.11(-0.01$ to 0.23$))$, although there was some evidence that some of the gains seen between KS1 and KS2 (0.50 (0.19 to 0.82)) were lost between KS2 and KS3 $(-0.35(-0.62$ to -0.07$))$. However, small numbers and wide CIs limit interpretation. There was little evidence that overall the trajectory of educational deciles was different between the two preterm groups $(\mathrm{p}=0.365)$.

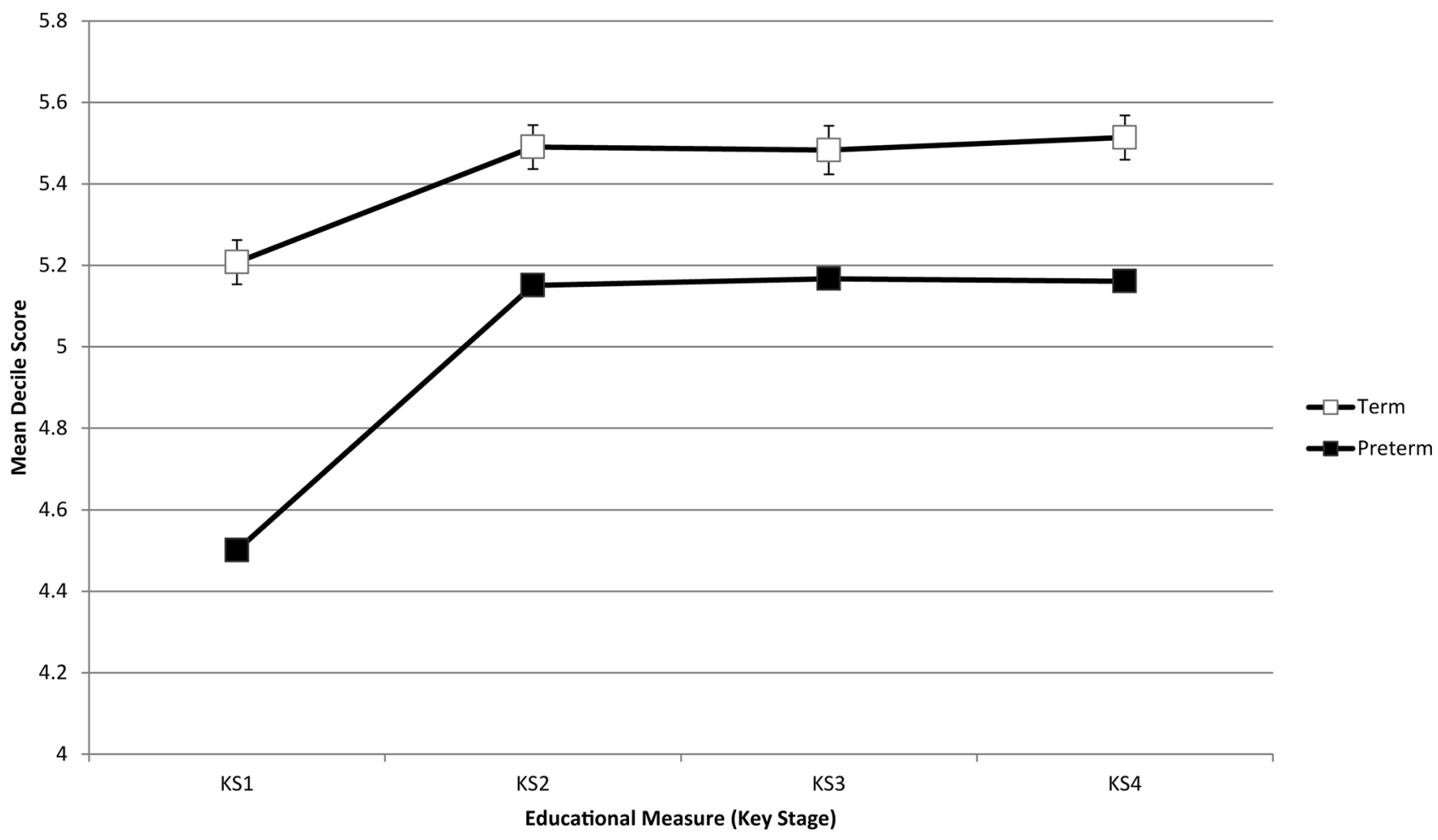

Figure 1 Summary measures of Key Stage scores at each time point, split by gestational age groups. 
Table 3 ROC curve analysis for the prediction of a poor KS4 score

\begin{tabular}{|c|c|c|c|c|c|c|c|c|}
\hline \multirow{2}{*}{$\begin{array}{l}\text { Educational } \\
\text { measures } \\
\text { included }\end{array}$} & \multicolumn{2}{|l|}{ Unadjusted } & \multicolumn{2}{|c|}{ Adjusted for social factors* } & \multicolumn{2}{|c|}{$\begin{array}{l}\text { Adjusted for social* } \\
\text { and antenatal factorst }\end{array}$} & \multicolumn{2}{|c|}{$\begin{array}{l}\text { Adjusted for social*, antenatal } \\
\text { and intrapartum } \neq \text { factors }\end{array}$} \\
\hline & AUC & $\mathbf{P}_{\text {interaction }}$ & AUC & $\mathbf{P}_{\text {interaction }}$ & AUC & $\mathbf{P}_{\text {interaction }}$ & AUC & $\mathbf{P}_{\text {interaction }}$ \\
\hline KS1 & $0.83(0.82$ to 0.84$)$ & 0.274 & $0.85(0.84$ to 0.86$)$ & 0.339 & 0.85 (0.84 to 0.86$)$ & 0.278 & 0.85 (0.84 to 0.86$)$ & 0.275 \\
\hline KS2 & $0.87(0.87$ to 0.88$)$ & 0.776 & $0.88(0.88$ to 0.89$)$ & 0.675 & 0.89 (0.88 to 0.89$)$ & 0.621 & $0.89(0.88$ to 0.89$)$ & 0.647 \\
\hline KS3 & 0.87 (0.86 to 0.87$)$ & 0.213 & 0.87 (0.87 to 0.88$)$ & 0.173 & $0.88(0.87$ to 0.88$)$ & 0.175 & $0.88(0.87$ to 0.88$)$ & 0.157 \\
\hline
\end{tabular}

Outcome is the area under the ROC curves. P values are for interaction with preterm status.

* Social factors: maternal age, socioeconomic group and education and ethnicity.

†Antenatal factors: gender, parity, weight, length and head circumference at birth.

¥Intrapartum factors: mode of delivery and maternal hypertension.

AUC, area under the curve; KS, Key Stage; ROC, receiver operating characteristics.

\section{DISCUSSION}

In this study, we have shown that while early educational measures are correlated with later measures for all children, the trajectory of educational measures in preterm infants varies compared with that of their term peers, but that prediction of their final outcome remains difficult. The data presented here indicate that most of the differences in trajectory seem to occur in the first few years at school, suggesting that preterm infants demonstrate some evidence of 'catch up' during the first few years at school, after which they appear to have similar educational trajectories to their peers.

One of the strengths of this work is that it is based on a population cohort study which prospectively collected data on many important covariates. In keeping with many cohort studies a degree of missing data is present, with around 14\% of eligible infants excluded due to a lack of outcome data. We used a multiple imputation technique to reduce the impact of missing confounders, but potential selection bias needs to be considered when interpreting the results presented here. It should also be noted that this cohort is based on preterm infants born more than 20 years ago and that some changes to the educational processes, and admission policies, are likely to have occurred during this time. However, these children born preterm demonstrated similar lower scores at school as those in more recent publications. $^{13} 14$

This work suggests, like other, ${ }^{4}$ that preterm infants continued to perform below their peers throughout their educational journey. However, their profile of attainment may be different, and some 'catch up' before the age of 11 seemed to occur. In contrast, a recent study of cognitive trajectories in extremely preterm infants was unable to find evidence of 'catch up', suggesting that the mechanisms here may be dependent on components other than purely cognitive skills. ${ }^{7}$ Our main results included a wider range of preterm birth, although subgroup analysis in this work seemed to suggest compatible if less precise results to the overall analysis. We have previously shown that educating children born preterm in their correct school year for their expected birth date (rather than their actual date) may be a cost-effective way of supporting these children. ${ }^{16}$ This work further suggests that preterm infants may need special consideration during their education and indeed may be particular sensitive to supportive interventions. ${ }^{15}{ }^{16}$ If replicated, this work supports the idea that early support may be differentially beneficial to ex-preterm infants in optimising their development.

The reduction in correlation between early measures and later ones for preterm infants (compared with term infants) may be due to a number of factors, including simple attenuation over time or increased mortality in a subset of very disabled children. While the educational journey of these infants may change because of the early low scores (eg, more support in the classroom), unless this intervention is differential on their preterm status (ie, more or less support is put in place because of their preterm birth) then the results would still appear to remain valid. Overall, we found little to suggest that the different educational trajectories were explained by special educational needs support.

While similar results were seen in the unadjusted and adjusted results, it may be the univariable results that are perhaps most relevant, as these are the results reviewed and assessed by teachers and parents. However, even without specifically targeted interventions, this work suggests that parents and teachers should be more optimistic about the final educational outcome with preterm infants, even when early measures would suggest otherwise.

Table 4 Mixed linear regression models for the mean KS decile difference between preterm and term infants

\begin{tabular}{|c|c|c|c|c|c|c|c|c|}
\hline \multirow[b]{2}{*}{ Covariate } & \multicolumn{2}{|l|}{ Unadjusted } & \multicolumn{2}{|c|}{ Adjusted for social factors* } & \multicolumn{2}{|c|}{$\begin{array}{l}\text { Adjusted for social* and antenatal } \\
\text { factors } t\end{array}$} & \multicolumn{2}{|c|}{$\begin{array}{l}\text { Adjusted for social*, antenatal }+ \\
\text { and intrapartum } \neq \text { factors }\end{array}$} \\
\hline & $\begin{array}{l}\text { Mean difference } \\
(95 \% \mathrm{Cl})\end{array}$ & $P$ values & $\begin{array}{l}\text { Mean difference } \\
(95 \% \mathrm{Cl})\end{array}$ & $P$ values & $\begin{array}{l}\text { Mean difference } \\
(95 \% \mathrm{Cl})\end{array}$ & $P$ values & $\begin{array}{l}\text { Mean difference } \\
(95 \% \mathrm{Cl})\end{array}$ & $P$ values \\
\hline Mean difference in score & $-0.77(-1.01$ to -0.52$)$ & $<0.001$ & $-0.49(-0.80$ to -0.18$)$ & 0.002 & $-0.59(-0.89$ to -0.13$)$ & 0.009 & $-0.46(-0.84$ to -0.07$)$ & 0.021 \\
\hline \multicolumn{9}{|c|}{ Change over four measures } \\
\hline Overall (KS1 to KS4) & $0.10(0.04$ to 0.17$)$ & 0.001 & $0.10(0.02$ to 0.17$)$ & 0.017 & 0.10 (0.01 to 0.19$)$ & 0.035 & 0.10 (0.01 to 0.19$)$ & 0.035 \\
\hline $\mathrm{KS} 1$ to $\mathrm{KS} 2$ & $0.24(-0.09$ to 0.40$)$ & 0.002 & $0.28(-0.08$ to 0.47$)$ & 0.006 & 0.34 (0.10 to 0.58$)$ & 0.005 & 0.34 (0.10 to 0.58$)$ & 0.005 \\
\hline $\mathrm{KS} 2$ to $\mathrm{KS} 3$ & $-0.02(-0.16$ to 0.12$)$ & 0.785 & $-0.02(-0.20$ to 0.16$)$ & 0.830 & $-0.14(-0.35$ to 0.07$)$ & 0.188 & $-0.15(-0.36$ to 0.07$)$ & 0.182 \\
\hline KS3 to KS4 & $0.13(-0.04$ to 0.30$)$ & 0.125 & $0.08(-0.14$ to 0.29$)$ & 0.496 & $0.18(-0.07$ to 0.44$)$ & 0.166 & $0.19(-0.07$ to 0.45$)$ & 0.149 \\
\hline
\end{tabular}

Measures are mean differences $(95 \% \mathrm{Cl})$ in the average $\mathrm{KS}$ decile and in the change seen over and between the four measures.

*Social factors: maternal age, socioeconomic group and education and ethnicity.

†Antenatal factors: gender, parity, weight, length and head circumference at birth.

łIntrapartum factors: mode of delivery and maternal hypertension.

KS, Key Stage. 


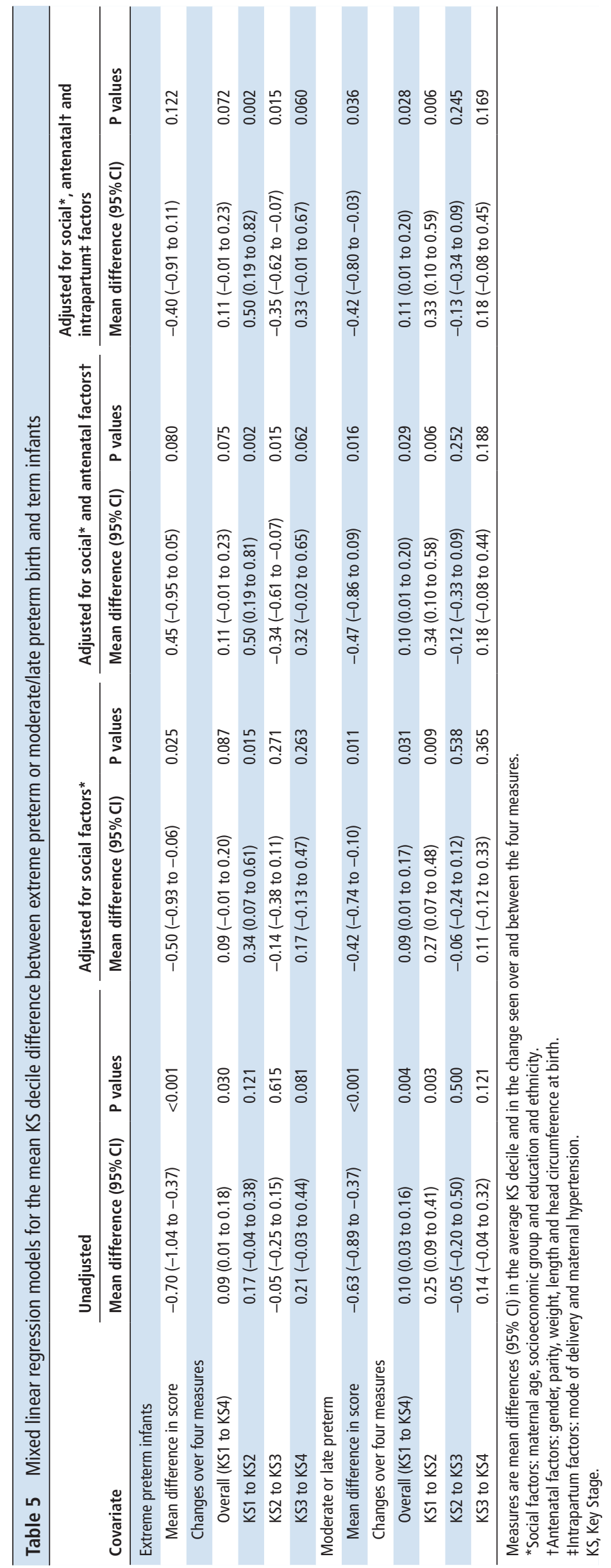




\section{CONCLUSIONS}

The results in this work suggest that preterm infants demonstrate some evidence of 'catch up' during the first few years at school, with a closing of the gap in low scores, and better prediction of their final score once they have reached KS2. Premature infants appear to have similar trajectories to their peers after this point. This further emphasises the importance of early schooling and environment in these infants and suggests that support, long after their premature birth, may have additional benefits.

Acknowledgements We are extremely grateful to all the families who took part in this study, the midwives for their help in recruiting them and the whole ALSPAC team, which includes interviewers, computer and laboratory technicians, clerical workers, research scientists, volunteers, managers, receptionists and nurses.

Contributors DO, AME and DE conceived the idea and developed the methodology. DO performed the statistical analysis and wrote the first draft of the paper. DO, AME and DE developed and approved the final manuscript. This publication is the work of the authors and DO will serve as guarantor for the contents of this paper.

Funding This research was specifically funded by North Bristol NHS Trust Springboard Fund (Round 10, R\&I ref: 3883). The UK Medical Research Council and the Wellcome Trust (Grant ref: 102215/2/13/2) and the University of Bristol provide core support for ALSPAC. A comprehensive list of grants funding is available on the ALSPAC website. The Project to Enhance ALSPAC through Record Linkage (PEARL) is funded by the Wellcome Trust (WT086118/Z/08/Z), John Macleod is the principal investigator (PI). Measures would include all record linkage to Primary Care records, Hospital Episode Statistics Records, Education Records, Child Looked After (CLA) and Child in Need (CIN) records, Geographical Records. 'Developing the ALSPAC longitudinal survey of children as a resource for education' was funded by the UK Department for Education and Skills (EOR/SBU/2002/121), Jean Golding was the PI. Measures would include all record linkage to National Pupil Database school-age educational records.

\section{Competing interests None declared.}

Patient consent Not required.

Ethics approval Ethical approval for the study was obtained from the ALSPAC Ethics and Law Committee and the Local Research Ethics Committees.

Provenance and peer review Not commissioned; externally peer reviewed.

Data sharing statement Data were obtained from ALSPAC (www.alspac.bristol. ac.uk) and access is not available from the authors.

Open access This is an open access article distributed in accordance with the Creative Commons Attribution 4.0 Unported (CC BY 4.0) license, which permits others to copy, redistribute, remix, transform and build upon this work for any purpose, provided the original work is properly cited, a link to the licence is given, and indication of whether changes were made. See: https://creativecommons.org/ licenses/by/4.0/.

\section{REFERENCES}

1 Odd D, Evans D, Emond A. Preterm birth, age at school entry and educational performance. PLoS One 2013:8:e76615.

2 Wood NS, Marlow N, Costeloe K, et al. Neurologic and developmental disability after extremely preterm birth. EPICure Study Group. N Engl J Med 2000;343:378-84.

3 Brouwer AJ, van Stam C, Uniken Venema M, et al. Cognitive and neurological outcome at the age of 5-8 years of preterm infants with post-hemorrhagic ventricular dilatation requiring neurosurgical intervention. Neonatology 2012;101:210-6.

4 Moster D, Lie RT, Markestad T. Long-term medical and social consequences of preterm birth. N Eng/ J Med 2008;359:262-73.

5 Ekeus C, Lindström K, Lindblad F, et al. Preterm birth, social disadvantage, and cognitive competence in Swedish 18- to 19-year-old men. Pediatrics 2010;125:e67-73.

6 Odd D, Evans D, Emond A. Preterm birth, age at school entry and long term educational achievement. PLoS One 2016;11:e0155157.

7 Linsell L, Johnson S, Wolke D, et al. Cognitive trajectories from infancy to early adulthood following birth before 26 weeks of gestation: a prospective, populationbased cohort study. Arch Dis Child 2018:103:363-70.

8 Boyd A, Golding J, Macleod J, et al. Cohort Profile: the 'children of the 90s'-the index offspring of the Avon Longitudinal Study of Parents and Children. Int J Epidemiol 2013;42:111-27.

9 Fraser A, Macdonald-Wallis C, Tilling K, et al. Cohort profile: the Avon Longitudinal Study of Parents and Children: ALSPAC mothers cohort. Int J Epidemiol 2013;42:97-110.

10 McNamee R. Confounding and confounders. Occup Environ Med 2003;60:227-34.

11 Office for National Statistics, 2013. Gestation-Specific Infant Mortality in England and Wales 2011. Cardiff ONS. Available at http://www.ons.gov.uk/ons/publications/rereference-tables.html?edition=tcm\%3A77-320891 (accessed 06 Sep 2014).

12 Royston P. Multiple imputation of missing values. Stata J 2004;3:227-41.

13 MacKay DF, Smith GC, Dobbie R, et al. Gestational age at delivery and special educational need: retrospective cohort study of 407,503 schoolchildren. PLoS Med 2010;7:e1000289.

14 Bhutta AT, Cleves MA, Casey PH, et al. Cognitive and behavioral outcomes of schoolaged children who were born preterm: a meta-analysis. JAMA 2002;288:728-37.

15 van Veen S, Aarnoudse-Moens CSH, Oosterlaan J, et al. Very preterm born children at early school age: Healthcare therapies and educational provisions. Early Hum Dev 2018:117:39-43.

16 Spittle A, Orton J, Anderson PJ, et al. Early developmental intervention programmes provided post hospital discharge to prevent motor and cognitive impairment in preterm infants. Cochrane Database Syst Rev 2015:CD005495. 